\title{
Fredholm-type theorem for boundary value problems for systems of nonlinear functional differential equations
}

Robert Hakl ${ }^{1 *}$ and Manuel Zamora ${ }^{2}$

Dedicated to Professor Ivan Kiguradze.

"Correspondence: hakl@ipm.cz ${ }^{1}$ Institute of Mathematics, Academy of Sciences of the Czech Republic, branch in Brno, Žižkova 22, Brno, 61662, Czech Republic

Full list of author information is available at the end of the article

\begin{abstract}
A Fredholm-type theorem for boundary value problems for systems of nonlinear functional differential equations is established. The theorem generalizes results known for the systems with linear or homogeneous operators to the case of systems with positively homogeneous operators.

MSC: $34 \mathrm{~K} 10$
\end{abstract}

Keywords: functional-differential equations; boundary value problems; existence of solutions

\section{Statement of the problem}

Consider the system of functional-differential equations

$$
u_{i}^{\prime}(t)=p_{i}\left(u_{1}, \ldots, u_{n}\right)(t)+f_{i}\left(u_{1}, \ldots, u_{n}\right)(t) \quad \text { for a.e. } t \in[a, b](i=1, \ldots, n)
$$

together with the boundary conditions

$$
\ell_{i}\left(u_{1}, \ldots, u_{n}\right)=h_{i}\left(u_{1}, \ldots, u_{n}\right) \quad(i=1, \ldots, n) .
$$

Here, $p_{i}, f_{i}: C\left([a, b] ; \mathbb{R}^{n}\right) \rightarrow L([a, b] ; \mathbb{R})$ are continuous operators satisfying Carathéodory conditions, i.e. for every $r>0$ there exists $q_{r} \in L\left([a, b] ; \mathbb{R}_{+}\right)$such that

$$
\sum_{i=1}^{n}\left(\left|p_{i}\left(u_{1}, \ldots, u_{n}\right)(t)\right|+\left|f_{i}\left(u_{1}, \ldots, u_{n}\right)(t)\right|\right) \leq q_{r}(t) \quad \text { for a.e. } t \in[a, b], \sum_{i=1}^{n}\left\|u_{i}\right\|_{C} \leq r,
$$

and $\ell_{i}, h_{i}: C\left([a, b] ; \mathbb{R}^{n}\right) \rightarrow \mathbb{R}$ are continuous functionals which are bounded on every ball by a constant, i.e. for every $r>0$ there exists $M_{r}>0$ such that

$$
\sum_{i=1}^{n}\left(\left|\ell_{i}\left(u_{1}, \ldots, u_{n}\right)\right|+\left|h_{i}\left(u_{1}, \ldots, u_{n}\right)\right|\right) \leq M_{r} \quad \text { whenever } \sum_{i=1}^{n}\left\|u_{i}\right\|_{C} \leq r .
$$

Furthermore, we assume that $p_{i}$ and $\ell_{i}$ satisfy the following condition: there exist positive real numbers $\lambda_{i j}$ and $\mu_{i}$ such that $\lambda_{i j} \lambda_{j m}=\lambda_{i m}$ whenever $i, j, m \in\{1, \ldots, n\}$, and for every

O2014 Hakl and Zamora; licensee Springer. This is an Open Access article distributed under the terms of the Creative Commons Attribution License (http://creativecommons.org/licenses/by/2.0), which permits unrestricted use, distribution, and reproduction in any medium, provided the original work is properly cited. 
$c>0$ and $\left(u_{k}\right)_{k=1}^{n} \in C\left([a, b] ; \mathbb{R}^{n}\right)$ we have

$$
\begin{aligned}
& c p_{i}\left(u_{1}, \ldots, u_{n}\right)(t)=p_{i}\left(c^{\lambda_{i 1}} u_{1}, \ldots, c^{\lambda_{i n}} u_{n}\right)(t) \quad \text { for a.e. } t \in[a, b], \\
& c^{\mu_{i}} \ell_{i}\left(u_{1}, \ldots, u_{n}\right)=\ell_{i}\left(c^{\lambda_{i 1}} u_{1}, \ldots, c^{\lambda_{i n}} u_{n}\right) .
\end{aligned}
$$

Remark 1 From the above-stated assumptions it follows that $\lambda_{i i}=1, \lambda_{i j}=1 / \lambda_{j i}$ for every $i, j \in\{1, \ldots, n\}$.

In the case when $p_{i}$ and $\ell_{i}$ are linear bounded operators and $f_{i}(\cdot, \ldots, \cdot)(t) \equiv q_{i}(t)$, $h_{i}(\cdot, \ldots, \cdot) \equiv c_{i}$, the relationship between the existence of a solution to problem (1), (2) and the existence of only the trivial solution to its corresponding homogeneous problem, socalled Fredholm alternative, is well known; for more details see e.g. [1-8] and references therein.

In 1966, Lasota established the Fredholm-type theorem in the case when $p_{i}$ and $\ell_{i}$ are homogeneous operators (see [9]). Recently, Fredholm-type theorems in the case when $p_{i}$ and $\ell_{i}$ are positively homogeneous operators were established by Kiguradze, Půža, Stavroulakis in [10] and also by Kiguradze, Šremr in [11].

In this paper we unify the ideas used in [11] and [9] to obtain a new Fredholm-type theorem for the case when $p_{i}$ and $\ell_{i}$ are positively homogeneous operators. The consequences of the obtained result for particular cases of problem (1), (2) are formulated at the end of the paper.

The following notation is used throughout the paper.

$\mathbb{N}$ is the set of all natural numbers;

$\mathbb{R}$ is the set of all real numbers, $\mathbb{R}_{+}=[0,+\infty)$;

$\mathbb{R}^{n}$ is the linear space of vectors $x=\left(x_{i}\right)_{i=1}^{n}$ with the elements $x_{i} \in \mathbb{R}$ endowed with the norm

$$
\|x\|=\sum_{i=1}^{n}\left|x_{i}\right| ;
$$

$C\left([a, b] ; \mathbb{R}^{n}\right)$ is the Banach space of continuous vector-valued functions $u=\left(u_{i}\right)_{i=1}^{n}:[a, b] \rightarrow \mathbb{R}^{n}$ with the norm

$$
\|u\|_{C}=\sum_{i=1}^{n} \max \left\{\left|u_{i}(t)\right|: t \in[a, b]\right\}
$$

$A C\left([a, b] ; \mathbb{R}^{n}\right)$ is the set of absolutely continuous vector-valued functions $u:[a, b] \rightarrow \mathbb{R}^{n}$;

$L([a, b] ; \mathbb{R})$ is the Banach space of Lebesgue integrable functions $p:[a, b] \rightarrow \mathbb{R}$ with the norm

$$
\|p\|_{L}=\int_{a}^{b}|p(s)| d s
$$

$L\left([a, b] ; \mathbb{R}_{+}\right)=\{p \in L([a, b] ; \mathbb{R}): p(t) \geq 0$ for a.e. $t \in[a, b]\} ;$

if $\Omega$ is a set then meas $\Omega$, int $\Omega, \bar{\Omega}$, and $\partial \Omega$ denotes the measure, interior, closure, and boundary of the set $\Omega$, respectively. 
By a solution to (1), (2) we understand a function $\left(u_{i}\right)_{i=1}^{n} \in A C\left([a, b] ; \mathbb{R}^{n}\right)$ satisfying (1) almost everywhere in $[a, b]$ and (2).

Notation 1 Define, for every $i \in\{1, \ldots, n\}$, the following functions:

$$
\begin{aligned}
& q_{i}(t, \rho) \stackrel{\text { def }}{=} \sup \left\{\left|f_{i}\left(u_{1}, \ldots, u_{n}\right)(t)\right|:\left\|u_{k}\right\|_{C} \leq \rho^{\lambda_{i k}}, k=1, \ldots, n\right\} \quad \text { for a.e. } t \in[a, b], \\
& \eta_{i}(\rho) \stackrel{\text { def }}{=} \sup \left\{\left|h_{i}\left(u_{1}, \ldots, u_{n}\right)\right|:\left\|u_{k}\right\|_{C} \leq \rho^{\frac{\lambda_{i k}}{\mu_{i}}}, k=1, \ldots, n\right\} .
\end{aligned}
$$

\section{Main result}

\section{Theorem 1 Let}

$$
\begin{aligned}
& \lim _{\rho \rightarrow+\infty} \int_{a}^{b} \frac{q_{i}(s, \rho)}{\rho} d s=0, \\
& \lim _{\rho \rightarrow+\infty} \frac{\eta_{i}(\rho)}{\rho}=0 \quad(i=1, \ldots, n) .
\end{aligned}
$$

If the problem

$$
\begin{aligned}
& u_{i}^{\prime}(t)=(1-\delta) p_{i}\left(u_{1}, \ldots, u_{n}\right)(t)-\delta p_{i}\left(-u_{1}, \ldots,-u_{n}\right)(t) \\
& \quad \text { for a.e. } t \in[a, b](i=1, \ldots, n), \\
& (1-\delta) \ell_{i}\left(u_{1}, \ldots, u_{n}\right)-\delta \ell_{i}\left(-u_{1}, \ldots,-u_{n}\right)=0 \quad(i=1, \ldots, n)
\end{aligned}
$$

has only the trivial solution for every $\delta \in[0,1 / 2]$, then problem (1), (2) has at least one solution.

The proof of Theorem 1 is based on the following result by Krasnosel'skii (see [12, Theorem 41.3, p.325]). We will formulate it in a form suitable for us.

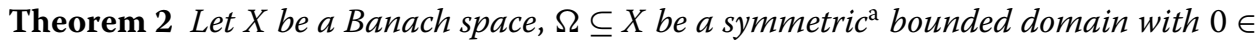
int $\Omega$. Let, moreover, $A: \bar{\Omega} \rightarrow \bar{\Omega}$ be a compact ${ }^{\mathrm{b}}$ continuous operator which has no fixed point on $\partial \Omega$. If, in addition,

$$
\frac{A(x)-x}{\|A(x)-x\|} \neq \frac{A(-x)+x}{\|A(-x)+x\|} \quad \text { for } x \in \partial \Omega
$$

then $A$ has a fixed point in $\Omega$, i.e. there exists $x_{0} \in \Omega$ such that $x_{0}=A\left(x_{0}\right)$.

Furthermore, to prove Theorem 1 we will need the following lemma.

Lemma 1 Let, for every $\delta \in[0,1 / 2]$, problem (6), (7) has only the trivial solution. Then there exists $r>0$ such that for any $\left(u_{i}\right)_{i=1}^{n} \in A C\left([a, b] ; \mathbb{R}^{n}\right)$ and any $\delta \in[0,1 / 2]$, the a priori estimate

$$
\sum_{k=1}^{n}\left\|u_{k}\right\|_{C}^{\lambda_{k 1}} \leq r \sum_{i=1}^{n}\left(\left\|\widetilde{f}_{i}\right\|_{L}^{\lambda_{i 1}}+\left|\widetilde{h}_{i}\right|^{\frac{\lambda_{i 1}}{\mu_{i}}}\right)
$$


holds, where

$$
\begin{aligned}
& \widetilde{f}_{i}(t) \stackrel{\text { def }}{=} u_{i}^{\prime}(t)-(1-\delta) p_{i}\left(u_{1}, \ldots, u_{n}\right)(t)+\delta p_{i}\left(-u_{1}, \ldots,-u_{n}\right)(t) \\
& \quad \text { for a.e. } t \in[a, b](i=1, \ldots, n), \\
& \widetilde{h}_{i} \stackrel{\text { def }}{=}(1-\delta) \ell_{i}\left(u_{1}, \ldots, u_{n}\right)-\delta \ell_{i}\left(-u_{1}, \ldots,-u_{n}\right) \quad(i=1, \ldots, n) .
\end{aligned}
$$

Proof Suppose on the contrary that for every $m \in \mathbb{N}$ there exist $\left(u_{i m}\right)_{i=1}^{n} \in A C\left([a, b] ; \mathbb{R}^{n}\right)$ and $\delta_{m} \in[0,1 / 2]$ such that

$$
\sum_{k=1}^{n}\left\|u_{k m}\right\|_{C}^{\lambda_{k 1}}>m \sum_{i=1}^{n}\left(\left\|\widetilde{f}_{i m}\right\|_{L}^{\lambda_{i 1}}+\left|\widetilde{h}_{i m}\right|^{\frac{\lambda_{i 1}}{\mu_{i}}}\right)
$$

where

$$
\begin{aligned}
& \widetilde{f}_{i m}(t) \stackrel{\text { def }}{=} u_{i m}^{\prime}(t)-\left(1-\delta_{m}\right) p_{i}\left(u_{1 m}, \ldots, u_{n m}\right)(t)+\delta_{m} p_{i}\left(-u_{1 m}, \ldots,-u_{n m}\right)(t) \\
& \quad \text { or a.e. } t \in[a, b](i=1, \ldots, n), \\
& \widetilde{h}_{i m} \stackrel{\text { def }}{=}\left(1-\delta_{m}\right) \ell_{i}\left(u_{1 m}, \ldots, u_{n m}\right)-\delta_{m} \ell_{i}\left(-u_{1 m}, \ldots,-u_{n m}\right) \quad(i=1, \ldots, n) .
\end{aligned}
$$

Put

$$
\begin{aligned}
& \rho_{m}=\sum_{k=1}^{n}\left\|u_{k m}\right\|_{C}^{\lambda_{k 1}} \quad \text { for } m \in \mathbb{N}, \\
& v_{i m}(t)=\frac{u_{i m}(t)}{\rho_{m}^{\lambda_{1 i}}} \quad \text { for } t \in[a, b], m \in \mathbb{N} .
\end{aligned}
$$

Then

$$
\sum_{i=1}^{n}\left\|v_{i m}\right\|_{C}^{\lambda_{i 1}}=1 \quad \text { for } m \in \mathbb{N}
$$

and from (10) and (11), in view of (3), (4), (12), and (13), we get

$$
\begin{aligned}
& \frac{\widetilde{f}_{i m}(t)}{\rho_{m}^{\lambda_{1 i}}}=v_{i m}^{\prime}(t)-\left(1-\delta_{m}\right) p_{i}\left(v_{1 m}, \ldots, v_{n m}\right)(t)+\delta_{m} p_{i}\left(-v_{1 m}, \ldots,-v_{n m}\right)(t) \\
& \quad \text { for a.e. } t \in[a, b](i=1, \ldots, n ; m \in \mathbb{N}), \\
& \frac{\widetilde{h}_{i m}}{\rho_{m} \lambda_{i i} \mu_{i}}=\left(1-\delta_{m}\right) \ell_{i}\left(v_{1 m}, \ldots, v_{n m}\right)-\delta_{m} \ell_{i}\left(-v_{1 m}, \ldots,-v_{n m}\right) \quad(i=1, \ldots, n ; m \in \mathbb{N}) .
\end{aligned}
$$

On the other hand, from (9) and (12) we have

$$
\sum_{i=1}^{n}\left(\left\|\frac{\widetilde{f}_{i m}}{\rho_{m}^{\lambda_{1 i}}}\right\|_{L}^{\lambda_{i 1}}+\left|\frac{\widetilde{h}_{i m}}{\rho_{m} \lambda_{1 i} \mu_{i}}\right|^{\frac{\lambda_{i 1}}{\mu_{i}}}\right)<\frac{1}{m} \quad \text { for } m \in \mathbb{N},
$$


whence, according to [13, Corollary IV.8.11] it follows that

$$
\lim _{\text {meas } E \rightarrow 0} \int_{E} \frac{\widetilde{f}_{i m}(s)}{\rho_{m}^{\lambda_{1 i}}} d s=0 \quad \text { uniformly for } m \in \mathbb{N}(i=1, \ldots, n) .
$$

Therefore, (14), (15), and (18) imply that the sequences $\left\{v_{i m}\right\}_{m=1}^{+\infty}(i=1, \ldots, n)$ are uniformly bounded and equicontinuous. Thus, according to Arzelà-Ascoli theorem, without loss of generality we can assume that there exist $\left(v_{i 0}\right)_{i=1}^{n} \in C\left([a, b] ; \mathbb{R}^{n}\right)$ and $\delta_{0} \in[0,1 / 2]$ such that

$$
\lim _{m \rightarrow+\infty} \delta_{m}=\delta_{0}, \quad \lim _{m \rightarrow+\infty}\left\|v_{i m}-v_{i 0}\right\|_{C}=0 \quad(i=1, \ldots, n) .
$$

Furthermore, (15)-(17) yield $\left(v_{i 0}\right)_{i=1}^{n} \in A C\left([a, b] ; \mathbb{R}^{n}\right)$ and show that it is a solution to (6), (7). However, (14) and (19) result in

$$
\sum_{i=1}^{n}\left\|v_{i 0}\right\|_{C}^{\lambda_{i 1}}=1
$$

which contradicts our assumptions.

Proof of Theorem 1 Let $X=C\left([a, b] ; \mathbb{R}^{n}\right) \times \mathbb{R}^{n}$ and for $x \in X$, i.e. $x=(u, \alpha)=\left(\left(u_{i}\right)_{i=1}^{n},\left(\alpha_{i}\right)_{i=1}^{n}\right)$, define the norm

$$
\|x\|=\|u\|_{C}+\|\alpha\| .
$$

Then $(X,\|\cdot\|)$ is a Banach space. Let the operators $T, F, A: X \rightarrow X$ be defined as follows:

$$
\begin{aligned}
& T(x) \stackrel{\text { def }}{=}\left(\left(u_{i}(a)+\alpha_{i}+\int_{a}^{t} p_{i}\left(u_{1}, \ldots, u_{n}\right)(s) d s\right)_{i=1}^{n},\left(\alpha_{i}+\ell_{i}\left(u_{1}, \ldots, u_{n}\right)\right)_{i=1}^{n}\right), \\
& F(x) \stackrel{\text { def }}{=}\left(\left(\int_{a}^{t} f_{i}\left(u_{1}, \ldots, u_{n}\right)(s) d s\right)_{i=1}^{n},\left(-h_{i}\left(u_{1}, \ldots, u_{n}\right)\right)_{i=1}^{n}\right), \\
& A(x) \stackrel{\text { def }}{=} T(x)+F(x),
\end{aligned}
$$

and consider the operator equation

$$
x=A(x) .
$$

It can easily be seen that problem (1), (2), and (23) are equivalent in the following sense: if $x=(u, \alpha)$ is a solution to (23), then $\alpha_{i}=0(i=1, \ldots, n)$ and $\left(u_{i}\right)_{i=1}^{n}$ is a solution to (1), (2); and vice versa if $\left(u_{i}\right)_{i=1}^{n}$ is a solution to (1), (2), then $x=(u, 0)$ is a solution to (23).

Let $r>0$ be such that the conclusion of Lemma 1 is valid. According to (5) we can choose $\rho_{0}>0$ such that

$$
\frac{1}{\rho_{0}} \sum_{i=1}^{n}\left(\left\|q_{i}\left(\cdot, \rho_{0}^{\lambda_{1 i}}\right)\right\|_{L}^{\lambda_{i 1}}+\left|\eta_{i}\left(\rho_{0}^{\lambda_{1 i} \mu_{i}}\right)\right|^{\frac{\lambda_{i 1}}{\mu_{i}}}\right)<\frac{1}{r}
$$

Let, moreover,

$$
\Omega=\left\{x \in X: \sum_{k=1}^{n}\left(\left\|u_{k}\right\|_{C}^{\lambda_{k 1}}+\left|\alpha_{k}\right|\right)<\rho_{0}\right\} .
$$


Now we will show that the operator $A$ has a fixed point in $\Omega$. According to Theorem 2 it is sufficient to show that

$$
A(x)-x \neq v(A(-x)+x) \quad \text { for } x \in \partial \Omega, v \in(0,1] .
$$

Assume on the contrary that there exist $x_{0}=\left(\left(u_{i 0}\right)_{i=1}^{n},\left(\alpha_{i 0}\right)_{i=1}^{n}\right) \in \partial \Omega$ and $v_{0} \in(0,1]$ such that

$$
A\left(x_{0}\right)-x_{0}=v_{0}\left(A\left(-x_{0}\right)+x_{0}\right) .
$$

Then from (26), in view of (20)-(22) we obtain

$$
x_{0}=\left(1-\delta_{0}\right) T\left(x_{0}\right)-\delta_{0} T\left(-x_{0}\right)+\left(1-\delta_{0}\right) F\left(x_{0}\right)-\delta_{0} F\left(-x_{0}\right),
$$

where $\delta_{0}=v_{0} /\left(1+v_{0}\right) \in(0,1 / 2]$, i.e.

$$
\begin{aligned}
& u_{i 0}(t)= u_{i 0}(a)+\alpha_{i 0}+\left(1-\delta_{0}\right) \int_{a}^{t} p_{i}\left(u_{10}, \ldots, u_{n 0}\right)(s) d s \\
&-\delta_{0} \int_{a}^{t} p_{i}\left(-u_{10}, \ldots,-u_{n 0}\right)(s) d s+\left(1-\delta_{0}\right) \int_{a}^{t} f_{i}\left(u_{10}, \ldots, u_{n 0}\right)(s) d s \\
&-\delta_{0} \int_{a}^{t} f_{i}\left(-u_{10}, \ldots,-u_{n 0}\right)(s) d s \quad \text { for } t \in[a, b](i=1, \ldots, n), \\
& \alpha_{i 0}=\alpha_{i 0}+\left(1-\delta_{0}\right) \ell_{i}\left(u_{10}, \ldots, u_{n 0}\right)-\delta_{0} \ell_{i}\left(-u_{10}, \ldots,-u_{n 0}\right) \\
&-\left(1-\delta_{0}\right) h_{i}\left(u_{10}, \ldots, u_{n 0}\right)+\delta_{0} h_{i}\left(-u_{10}, \ldots,-u_{n 0}\right) \quad(i=1, \ldots, n) .
\end{aligned}
$$

Now from (27) and (28) it follows that $\left(u_{i}\right)_{i=1}^{n} \in A C\left([a, b] ; \mathbb{R}^{n}\right)$,

$$
\begin{aligned}
& \alpha_{i 0}=0 \quad(i=1, \ldots, n), \\
& u_{i 0}^{\prime}(t)=\left(1-\delta_{0}\right) p_{i}\left(u_{10}, \ldots, u_{n 0}\right)(t)-\delta_{0} p_{i}\left(-u_{10}, \ldots,-u_{n 0}\right)(t) \\
& +\left(1-\delta_{0}\right) f_{i}\left(u_{10}, \ldots, u_{n 0}\right)(t)-\delta_{0} f_{i}\left(-u_{10}, \ldots,-u_{n 0}\right)(t) \\
& \text { for a.e. } t \in[a, b](i=1, \ldots, n) \text {, } \\
& \left(1-\delta_{0}\right) \ell_{i}\left(u_{10}, \ldots, u_{n 0}\right)-\delta_{0} \ell_{i}\left(-u_{10}, \ldots,-u_{n 0}\right) \\
& =\left(1-\delta_{0}\right) h_{i}\left(u_{10}, \ldots, u_{n 0}\right)-\delta_{0} h_{i}\left(-u_{10}, \ldots,-u_{n 0}\right) \quad(i=1, \ldots, n) .
\end{aligned}
$$

Moreover, since $x_{0} \in \partial \Omega$, on account of (25) and (29) we have

$$
\rho_{0}=\sum_{k=1}^{n}\left\|u_{k 0}\right\|_{C}^{\lambda_{k 1}}
$$

Now the equality (32), according to Notation 1, implies

$$
\begin{aligned}
& \left|\left(1-\delta_{0}\right) f_{i}\left(u_{10}, \ldots, u_{n 0}\right)(t)-\delta_{0} f_{i}\left(-u_{10}, \ldots,-u_{n 0}\right)(t)\right| \leq q_{i}\left(t, \rho_{0}^{\lambda_{1 i}}\right) \\
& \quad \text { for a.e. } t \in[a, b](i=1, \ldots, n), \\
& \left|\left(1-\delta_{0}\right) h_{i}\left(u_{10}, \ldots, u_{n 0}\right)-\delta_{0} h_{i}\left(-u_{10}, \ldots,-u_{n 0}\right)\right| \leq \eta_{i}\left(\rho_{0}^{\lambda_{1 i} \mu_{i}}\right) \quad(i=1, \ldots, n) .
\end{aligned}
$$


Therefore, in view of Lemma 1, with respect to (30)-(34) we obtain

$$
\rho_{0} \leq r \sum_{i=1}^{n}\left(\left\|q_{i}\left(\cdot, \rho_{0}^{\lambda_{1 i}}\right)\right\|_{L}^{\lambda_{i 1}}+\left|\eta_{i}\left(\rho_{0}^{\lambda_{1 i} \mu_{i}}\right)\right|^{\frac{\lambda_{i 1}}{\mu_{i}}}\right) .
$$

However, the latter inequality contradicts (24).

\section{Corollaries}

If the operators $p_{i}$ and $\ell_{i}$ are homogeneous, i.e. if moreover

$$
\begin{aligned}
& p_{i}\left(-u_{1}, \ldots,-u_{n}\right)(t)=-p_{i}\left(u_{1}, \ldots, u_{n}\right)(t) \\
& \quad \text { for a.e. } t \in[a, b],\left(u_{k}\right)_{k=1}^{n} \in C\left([a, b] ; \mathbb{R}^{n}\right)(i=1, \ldots, n), \\
& \ell_{i}\left(-u_{1}, \ldots,-u_{n}\right)=-\ell_{i}\left(u_{1}, \ldots, u_{n}\right), \quad\left(u_{k}\right)_{k=1}^{n} \in C\left([a, b] ; \mathbb{R}^{n}\right)(i=1, \ldots, n),
\end{aligned}
$$

then from Theorem 1 we obtain the following assertion.

Corollary 1 Let (5), (35), and (36) be fulfilled. If the problem

$$
\begin{aligned}
& u_{i}^{\prime}(t)=p_{i}\left(u_{1}, \ldots, u_{n}\right)(t) \quad \text { for a.e. } t \in[a, b](i=1, \ldots, n), \\
& \ell_{i}\left(u_{1}, \ldots, u_{n}\right)=0 \quad(i=1, \ldots, n)
\end{aligned}
$$

has only the trivial solution then problem (1), (2) has at least one solution.

For a particular case when $p_{i}$ are defined by

$$
\begin{aligned}
& p_{i}\left(u_{1}, \ldots, u_{n}\right)(t) \stackrel{\text { def }}{=} \widetilde{p}_{i}(t)\left|u_{i+1}\left(\tau_{i}(t)\right)\right|^{\lambda_{i}} \operatorname{sgn} u_{i+1}\left(\tau_{i}(t)\right) \\
& \quad \text { for a.e. } t \in[a, b](i=1, \ldots, n-1), \\
& p_{n}\left(u_{1}, \ldots, u_{n}\right)(t) \stackrel{\text { def }}{=} \widetilde{p}_{n}(t)\left|u_{1}\left(\tau_{n}(t)\right)\right|^{\lambda_{n}} \operatorname{sgn} u_{1}\left(\tau_{n}(t)\right) \text { for a.e. } t \in[a, b],
\end{aligned}
$$

where $\widetilde{p}_{i} \in L([a, b] ; \mathbb{R})$ and $\tau_{i}:[a, b] \rightarrow[a, b]$ are measurable functions, we have the following assertion.

Corollary 2 Let (5), (36), (39), and (40) be fulfilled. Let, moreover,

$$
\prod_{i=1}^{n} \lambda_{i}=1
$$

and let problem (37), (38) have only the trivial solution. Then problem (1), (2) has at least one solution.

Namely, for a two-dimensional system of ordinary equations and a particular case of boundary conditions we get the following.

Corollary 3 Let $\lambda_{1} \lambda_{2}=1$, and let

$$
\begin{aligned}
& u_{1}^{\prime}=\tilde{p}_{1}(t)\left|u_{2}\right|^{\lambda_{1}} \operatorname{sgn} u_{2}, \quad u_{2}^{\prime}=\widetilde{p}_{2}(t)\left|u_{1}\right|^{\lambda_{2}} \operatorname{sgn} u_{1}, \\
& u_{1}(a)-c_{1} u_{1}(b)=0, \quad u_{2}(a)-c_{2} u_{2}(b)=0
\end{aligned}
$$


with $\widetilde{p}_{1}, \widetilde{p}_{2} \in L([a, b] ; \mathbb{R}), c_{1}, c_{2} \in \mathbb{R}$ have only the trivial solution. Then the problem

$$
\begin{aligned}
& u_{1}^{\prime}=\widetilde{p}_{1}(t)\left|u_{2}\right|^{\lambda_{1}} \operatorname{sgn} u_{2}+f_{1}(t), \quad u_{2}^{\prime}=\widetilde{p}_{2}(t)\left|u_{1}\right|^{\lambda_{2}} \operatorname{sgn} u_{1}+f_{2}(t), \\
& u_{1}(a)-c_{1} u_{1}(b)=h_{1}, \quad u_{2}(a)-c_{2} u_{2}(b)=h_{2}
\end{aligned}
$$

has at least one solution for every $f_{1}, f_{2} \in L([a, b] ; \mathbb{R})$ and $h_{1}, h_{2} \in \mathbb{R}$.

The particular case of the system discussed in Corollary 3 is so-called second-order differential equation with $\lambda$-Laplacian. Therefore, in the case when $\widetilde{p}_{1} \equiv 1$, Corollary 3 yields the following.

\section{Corollary 4 Let the problem}

$$
\begin{aligned}
& \left(\Phi_{\lambda}\left(u^{\prime}(t)\right)\right)^{\prime}=p(t) \Phi_{\lambda}(u(t)), \\
& u(a)-c_{1} u(b)=0, \quad u^{\prime}(a)-c_{2} u^{\prime}(b)=0
\end{aligned}
$$

with $p \in L([a, b] ; \mathbb{R}), \Phi_{\lambda}(x)=|x|^{\lambda} \operatorname{sgn} x, c_{1}, c_{2} \in \mathbb{R}$ have only the trivial solution. Then the problem

$$
\begin{aligned}
& \left(\Phi_{\lambda}\left(u^{\prime}(t)\right)\right)^{\prime}=p(t) \Phi_{\lambda}(u(t))+f(t), \\
& u(a)-c_{1} u(b)=h_{1}, \quad u^{\prime}(a)-c_{2} u^{\prime}(b)=h_{2}
\end{aligned}
$$

has at least one solution for every $f \in L([a, b] ; \mathbb{R})$ and $h_{1}, h_{2} \in \mathbb{R}$.

\section{Competing interests}

The authors declare that they have no competing interests.

\section{Authors' contributions}

$\mathrm{RH}$ and $\mathrm{MZ}$ obtained the results in a joint research. Both authors read and approved the final manuscript.

\section{Author details}

'Institute of Mathematics, Academy of Sciences of the Czech Republic, branch in Brno, Žižkova 22, Brno, 61662, Czech Republic. ${ }^{2}$ Departamento de Matemática, Facultad de Ciencias, Universidad del Bío-Bío, Casilla 5-C, Concepción, 4051381, Chile.

\section{Acknowledgements}

Robert Hakl has been supported by RVO: 67985840. Manuel Zamora has been supported by Ministerio de Educación y Ciencia, Spain, project MTM2011-23652, and by a postdoctoral grant from University of Granada.

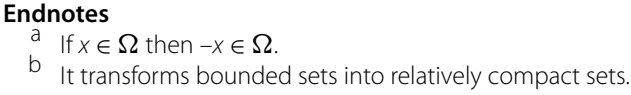

a If $x \in \Omega$ then $-x \in \Omega$.

b It transforms bounded sets into relatively compact sets.

Received: 30 January 2014 Accepted: 29 April 2014 Published: 13 May 2014

\section{References}

1. Azbelev, NV, Maksimov, VP, Rakhmatullina, LF: Introduction to the Theory of Functional Differential Equations. Nauka, Moscow (1991)

2. Azbelev, NV, Maksimov, VP, Rakhmatullina, LF: Methods of Modern Theory of Linear Functional Differential Equations. R\&C Dynamics, Moscow (2000)

3. Bravyi, E: A note on the Fredholm property of boundary value problems for linear functional differential equations. Mem. Differ. Equ. Math. Phys. 20, 133-135 (2000)

4. Hakl, R, Lomtatidze, A, Stavroulakis, IP: On a boundary value problem for scalar linear functional differential equations. Abstr. Appl. Anal. 9(1), 45-67 (2004) 
5. Hakl, R, Mukhigulashvili, S: On a boundary value problem for $n$-th order linear functional differential systems. Georgian Math. J. 12(2), 229-236 (2005)

6. Kiguradze, I, Půža, B: On boundary value problems for systems of linear functional differential equations. Czechoslov. Math. J. 47(2), 341-373 (1997)

7. Kiguradze, I, P̊̊žă, B: Boundary Value Problems for Systems of Linear Functional Differential Equations. Folia Facult. Scien. Natur. Univ. Masarykiana Brunensis. Mathematica, vol. 12. Masaryk University, Brno (2003)

8. Schwabik, Š, Tvrdý, M, Vejvoda, O: Differential and Integral Equations: Boundary Value Problems and Adjoints. Academia, Praha (1979)

9. Lasota, A: Une généralisation du premier théorème de Fredholm et ses applications à la théorie des équations différentielles ordinaires. Ann. Pol. Math. 18, 65-77 (1966)

10. Kiguradze, I, Pǔža, B, Stavroulakis, IP: On singular boundary value problems for functional differential equations of higher order. Georgian Math. J. 8(4), 791-814 (2001)

11. Kiguradze, I, Šremr, J: Solvability conditions for non-local boundary value problems for two-dimensional half-linear differential systems. Nonlinear Anal. TMA 74(17), 6537-6552 (2011)

12. Krasnosel'skii, MA, Zabreiko, PP: Geometricheskie metody nelineinogo analiza. Nauka, Moscow (1975)

13. Dunford, N, Schwartz, JT: Linear Operators: General Theory. Wiley-Interscience, New York (1961)

10.1186/1687-2770-2014-113

Cite this article as: Hakl and Zamora: Fredholm-type theorem for boundary value problems for systems of nonlinear functional differential equations. Boundary Value Problems 2014, 2014:113

\section{Submit your manuscript to a SpringerOpen ${ }^{\circ}$ journal and benefit from:}

- Convenient online submission

- Rigorous peer review

- Immediate publication on acceptance

Open access: articles freely available online

- High visibility within the field

- Retaining the copyright to your article 